Conf $-950412--32$

UCRL-JC-120336

PREPRINT

\title{
THE INFLUENCE OF GRAIN STRUCTURE ON THE RELIABILITY OF NARROW AL-BASED INTERCONNECTS
}

\author{
S. H. Kang \\ C. Kim \\ François Y. Genin \\ J. W. Morris, Jr.
}

This paper was prepared for submittal to

Materials Research Society, Symposium T

in San Francisco, CA on April 16 - 21, 1995.

May 1995

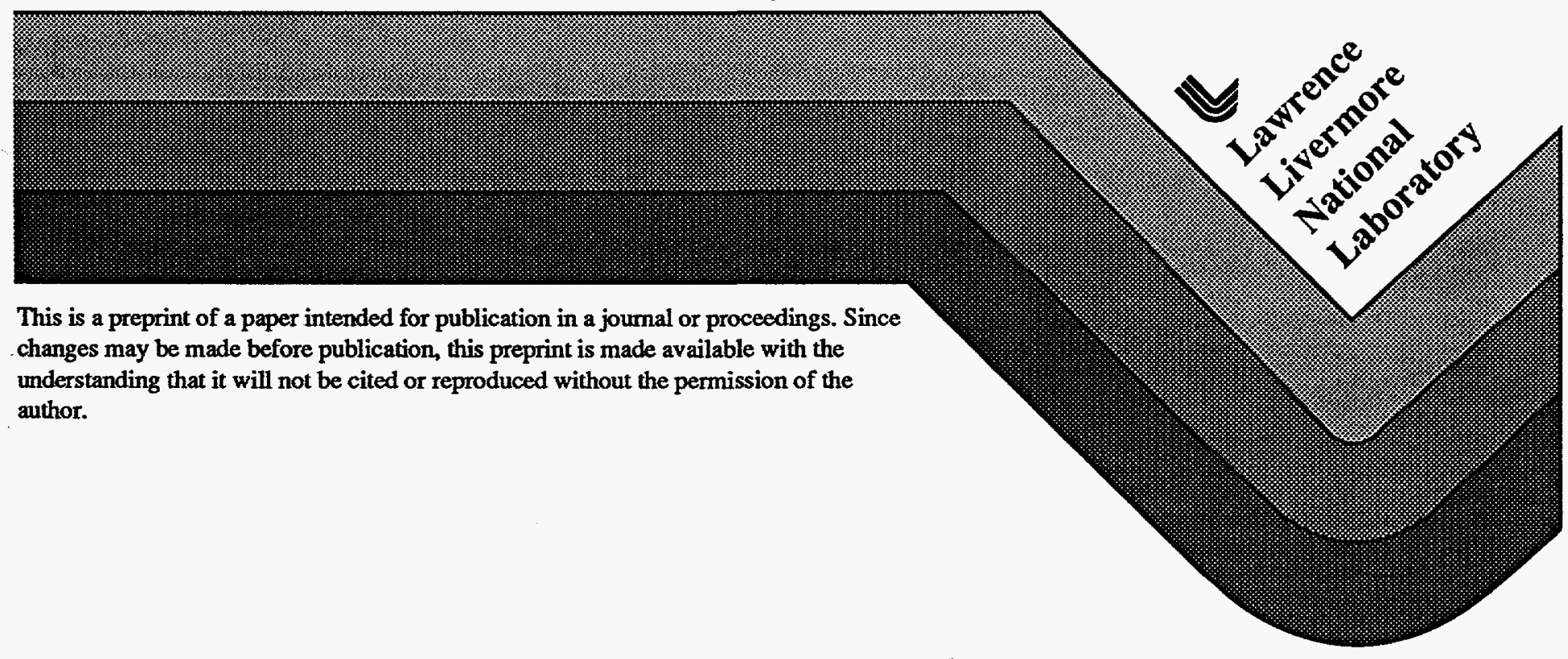




\section{DISCLAIMER}

This report was prepared as an account of work sponsored by an agency of the United States Government. Neither the United States Government nor any agency thereof, nor any of their employees, make any warranty, express or implied, or assumes any legal liability or responsibility for the accuracy, completeness, or usefulness of any information, apparatus, product, or process disclosed, or represents that its use would not infringe privately owned rights. Reference herein to any specific commercial product, process, or service by trade name, trademark, manufacturer, or otherwise does not necessarily constitute or imply its endorsement, recommendation, or favoring by the United States Government or any agency thereof. The views and opinions of authors expressed herein do not necessarily state or reflect those of the United States Government or any agency thereof. 


\section{DISCLAIMER}

Portions of this document may be illegible in electronic image products. Images are produced from the best available original document. 


\title{
THE INFLUENCE OF GRAIN STRUCTURE ON THE RELIABILITY OF NARROW AL-BASED INTERCONNECTS
}

S.H.Kang, C.Kim, F.Y.Génin* and J.W.Morris,Jr.

Center for Advanced Materials, Lawrence Berkeley Laboratory and the Department of Materials Science and Engineering, University of California, Berkeley, CA 94720

*Chemistry and Materials Science, Lawrence Livermore National Laboratory, Livermore, CA 94550

\begin{abstract}
- The work reported here concems the effect of grain structure on electromigration failure in pure $\mathrm{Al}$ and $\mathrm{Al}-2 \mathrm{wt}$.\% Cu-1wt.\%Si lines. The grain structures of fine lines were controlled by annealing after patterning to promote the formation of "bamboo" structures. Significant improvements in the median time to failure (MTF) and the deviation of the time to failure (DTF) were observed with the development of near-bamboo structures with polygranular-segment lengths shorter than $\sim 5 \mu \mathrm{m}$. The most common failure sites are voids or slits across bamboo grains at the upstream ends of polygranular segments. The time-to-failure decreases with the polygranular segment length, and can be significantly enhanced by controlling the grain structure.
\end{abstract}

\section{INTRODUCTION}

Electromigration failure occurs by the accumulation of vacancies at sites where microstructural irregularities create a divergence in the current-enhanced vacancy flux [1]. Recent studies have shown that the predominant failure sites in narrow interconnects with partially "bamboo" grain structure are located at the longest polygranular segments in the line [2]. It has been also reported that the electromigration lifetime increases significantly as the number of grain-boundary triple junctions per unit line length decreases [3]. These reports suggest that the control of grain structure, to reduce the lengths of polygranular segments and the number of grains in each polygranular segment, will enhance the reliability of the interconnects.

The work reported here studies the influence of grain structure on electromigration failure in pure $\mathrm{Al}$ and $\mathrm{Al}-2 \mathrm{wt} \% \mathrm{Cu}-1 \mathrm{wt} . \% \mathrm{Si}$ lines with $1 \mu \mathrm{m}$ and $1.3 \mu \mathrm{m}$ widths, respectively. It is well documented that both the median time to failure (MTF) and the deviation of the time to failure (DTF) change with the width of lines patterned from a given grain structure [4-7]. The present work focuses on the influence of grain structure at given width. The structure is modified by annealing pre-pattemed lines at moderate temperature to create microstructures that contain a high fraction of bamboo grains. Given prior work [2] showing that the failure kinetics of lines with partially bamboo structures are controlled by the longest residual polygranular segments, the MTF should be increased by annealing treatments that reduce the length of the longest polygranular segments, and the DTF should be reduced by annealing treatments that preferentially attack the longest polygranular segments to produce more uniform distributions of maximum segment lengths.

\section{EXPERIMENTAL PROCEDURE}

Pure Al films were deposited by sputtering at room temperature on p-type Si wafers coated with a thermally grown native oxide, $0.07 \mu \mathrm{m}$ in thickness. The sputtered films were de'posited to a thickness of $0.5 \mu \mathrm{m}$. The films were patterned into test lines of $1 \mu \mathrm{m}$ width by stanidard photolithography and plasma dry etching techniques. The test lines were annealed for varilous times at $480^{\circ} \mathrm{C}$ in an Ar atmosphere. Si diffusion from the underlayer is negligible for these 
annealing conditions. Electromigration tests were then performed at $225^{\circ} \mathrm{C}$ at a current density of $1.2 \times 10^{6} \mathrm{~A} / \mathrm{cm}^{2}$. The test results were analyzed based on the fact that the changes in MTF and DTF were caused by different grain structures. Since the lines had no alloying elements and were unpassivated, the different annealing times would create only the different grain structures. In addition to pure $\mathrm{Al}$ lines, $\mathrm{Al}-2 \mathrm{wt} . \% \mathrm{Cu}-1 \mathrm{wt} . \%$ Si lines of $1.3 \mu \mathrm{m}$ in width were prepared by the same fabrication methods in order to compare the results of pure Al lines with those of Al-alloy lines. After the lines were annealed in a mixture of $\mathrm{H}_{2}$ and $\mathrm{N}_{2}$, the electromigration test was performed at the same temperature under a higher current density of $3.0 \times 10^{6} \mathrm{~A} / \mathrm{cm}^{2}$. The grain structures of all the lines were studied by using transmission electron microscopy (TEM) and scanning electron microscopy (SEM).

\section{RESULTS AND DISCUSSION}

\section{Grain-Structure Control in Pure Al Lines}

Electromigration tests were performed for a group of as-patterned lines and four groups of lines that had been annealed for $5 \mathrm{~min}$., $15 \mathrm{~min}$., $30 \mathrm{~min}$. and $60 \mathrm{~min}$. at $480^{\circ} \mathrm{C}$. The failure times are plotted in Fig. 1. The failure times were fitted to log-normal distribution curves, and the MTF and the DTF calculated from these distributions. The results are plotted in Fig. 2. It is. apparent that there is a decrease in MTF after $5 \mathrm{~min}$. of annealing, however, further annealing causes a dramatic increase in MTF. The DTF increases gradually until the annealing time exceeds $30 \mathrm{~min}$., and begins to decrease when the annealing time exceeds $60 \mathrm{~min}$..

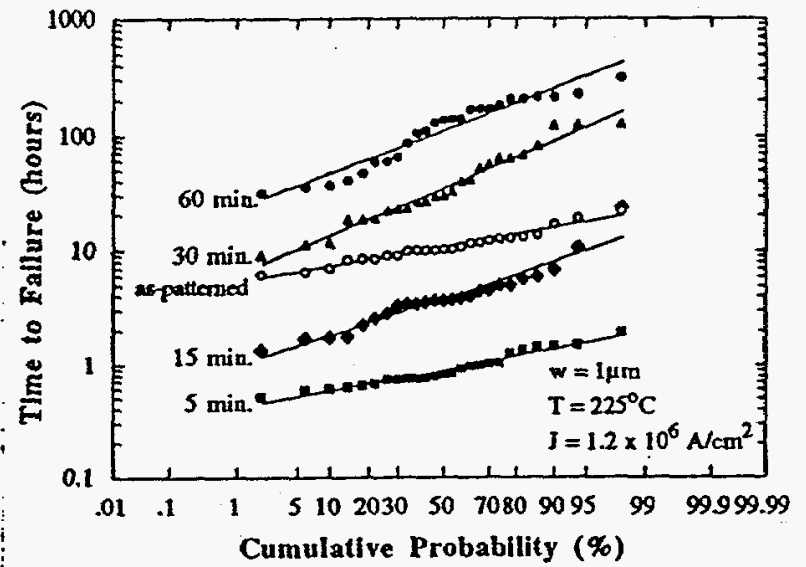

Fig. 1 Time-to-failure distributions with annealing times for pure Al lines.

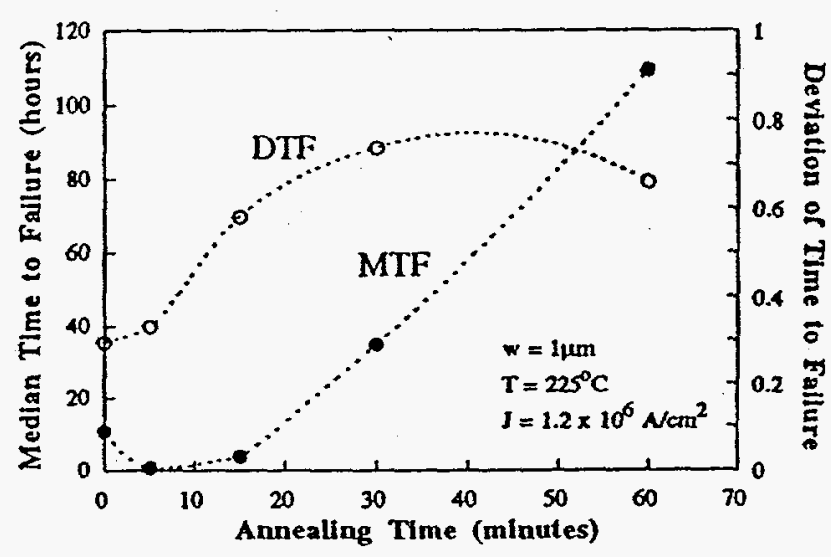

Fig. 2 Variations in MTF and DTF with annealing times for pure Al lines.

The variations in the MTF and DTF shown in Fig. 2 must be a consequence of the evolution of the grain structure during annealing, since this is the only variable in the test. The changes in the grain structure are illustrated in the transmission electron micrographs shown in Fig. 3. Before annealing, the lines were fine-grained along their whole lengths (Fig. 3-(a)). The average igrain size was $0.13 \mu \mathrm{m}$. During the first $5 \mathrm{~min}$. of annealing, bamboo grains develop at isolated. points along the line. dividing the line into very long polygranular segments that contain fine igrains (Fig. 3-(b)). This microstructure minimizes the MTF. This decrease in MTF is expected. While the fine grain structure of the as-patterned lines leads to a high flux of Al atoms, which can migrate along grain boundaries, the relative uniformity of the grain structure minimizes the flux divergence that causes accumulation of vacancies and voiding. On the other hand, the long polygranular segments present after 5 min. annealing have microstructural discontinuities at their terminal points that create large flux divergences. Hence, the reliability is degraded by a short period, of annealing. 


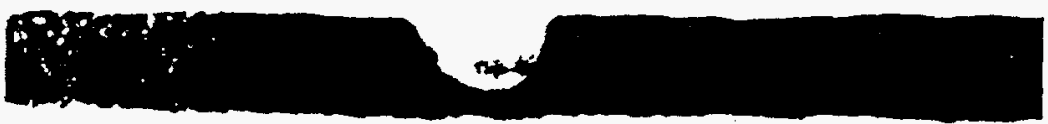

b
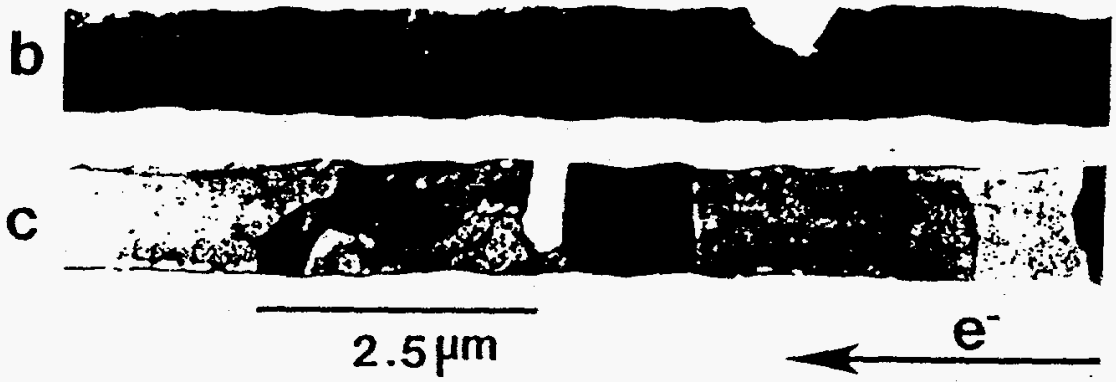

Fig. 3 TEM micrographs showing the grain structures of (a) an as-pattemed line, (b) a line annealed for $5 \mathrm{~min}$., and (c) a line annealed for $60 \mathrm{~min}$. at $480^{\circ} \mathrm{C}$.

The MTF is dramatically increased when the annealing time is raised to 60 min.. The DTF also increases, but retains a relatively small value, so the time to first failure increases significantly. This improvement in performance is associated with three microstructural changes. First, as illustrated in Fig. 3-(c), the polygranular segments are broken up by grain growth so that their maximum lengths are significantly decreased. Second, the residual polygranular segments contain relatively large grains; this lowers the vacancy flux within them and decreases the flux divergence at their boundaries. Third, the preferential destruction of the longest polygranular segments modulates the variation in the length of the longest polygranular segments from line to line, maintaining a low value of the DTF. The results suggest that, while perfect-bamboo structures may be the best choice for Al interconnects [8], near-bamboo structures with short polygranular segments and a narrow distribution of segment lengths can be effectively used as reliable interconnects.

In prior work, the MTF and DTF have been plotted as a function of the effective line width, W/G, the ratio of line width to mean grain size [5-6]. The results show that while the MTF increases dramatically as the effective line width decrease in the "bamboo" regime, the DTF also increases, with the result that there is little improvement in the time to first failure, which is the relevant design parameter. As the data in Fig. 2 show, however, annealing the line after patterning leads to a similar (or greater) increase in the MTF, while the DTF quickly saturates. The net result is a significant increase in the time to first failure. The apparent reason for this benefit is that the longer polygranular segments are preferentially attacked and broken up during annealing, so that the probability of finding a very long polygranular segment becomes low. Statistical studies of polygranular segment length as a function of annealing time are underway to: quantify this effect.

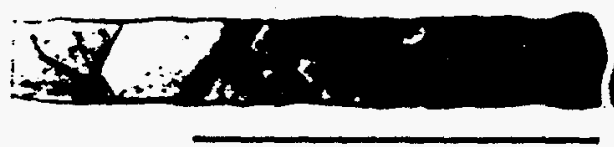

$4.2 \mu \mathrm{m}$

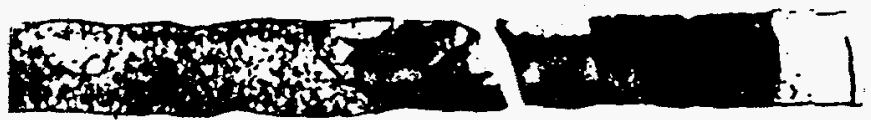

$1.5 \mu \mathrm{m}$
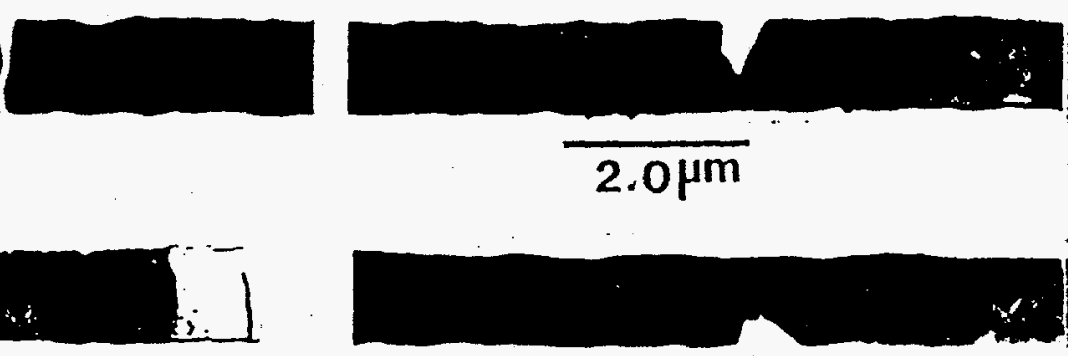

$3.0 \mu \mathrm{m}$

Fig. 4 TEM micrographs showing the typical damage and failure sites in near-bamboo Al lines annealed for $60 \mathrm{~min}$. at $480^{\circ} \mathrm{C}$. The polygranular-segment lengths are also shown. 
Fig. 3 also shows the typical morphologies of voids in pure Al lines which were examined using TEM. Except for the lines which had a uniform polygranular structure in the entire length, the dominant failure mechanism was the formation of a void in the bamboo grain which was located at the upstream end of a polygranular segment. To illustrate this argument, typical voids which were observed in the 60-min.-annealed lines are shown in Fig. 4. It appears that, while the void shapes look different, all the voids are related to the polygranular segments.

It has been reported that, if a polygranular segment in near-bamboo structures is shorter than the "Blech length" for a given current density, the electromigration-induced voids associated with the polygranular segment should not occur [5,9]. Since Fig. 3-(c) and Fig. 4 show typical polygranular segments obtained from near-bamboo structures, it is useful to compare the lengths of those polygranular segments with the Blech length. For a current density of $1.2 \times 10^{6} \mathrm{~A} / \mathrm{cm}^{2}$, this length is $5-10 \mu \mathrm{m}$ [9]. Note the void locations and the polygranular-segment lengths shown in Fig. 3-(c) and Fig. 4. The voids still occur near the ends of the polygranular segments, even though they are shorter than the Blech length. This result suggests that the flux divergence associated with short polygranular segments can still create void failures, even in near-bamboo structures. On the other hand, it seems that the void shape and the final failure location depend on the different void-growing pattern which may result from the different nature of the bamboo grain next to the polygranular segment.

The observation of the near-bamboo Al lines is in agreement with the recent suggestion by Lloyd [10]. It was suggested that, while different diffusion paths such as an interface or a lattice can be a major role for the failures near short polygranular segments, the grain boundary diffusion in the short polygranular segments possibly contributes to the electromigration failures near those segments. Although a clear feature of this phenomenon is not yet understood, provided that polygranular segments exist, the electromigration failure would be closely related to the condensation of vacancies which are ejected from the polygranular segments.

\section{Grain-Structure Control in Al-2wt.\%Cu-1wt.\%Si Lines}

Following tests on pure Al lines, we studied the influence of post-patterning annealing on $\mathrm{Al}-2 \mathrm{wt} . \% \mathrm{Cu}-1 \mathrm{wt}$.\%Si lines. The average grain size of the as-deposited film was $0.2 \mu \mathrm{m}$, however, before patterning, a rapid thermal annealing (RTA) was carried out for $5 \mathrm{~min}$. at $500^{\circ} \mathrm{C}$, which increases the average grain size to $0.9 \mu \mathrm{m}$ The lines were then patterned and annealed for $5 \mathrm{~min} ., 30 \mathrm{~min} ., 60 \mathrm{~min}$. and $120 \mathrm{~min}$. at $480^{\circ} \mathrm{C}$. Fig. 5 and Fig. 6 show the results of subsequent electromigration test at $225^{\circ} \mathrm{C}$ under a current density of $3.0 \times 10^{6} \mathrm{~A} / \mathrm{cm}^{2}$. The higher current density was used to achieve failure in reasonably short times in these lines, which, because of the $\mathrm{Cu}$ content, are more resistant to electromigration than the pure Al lines.

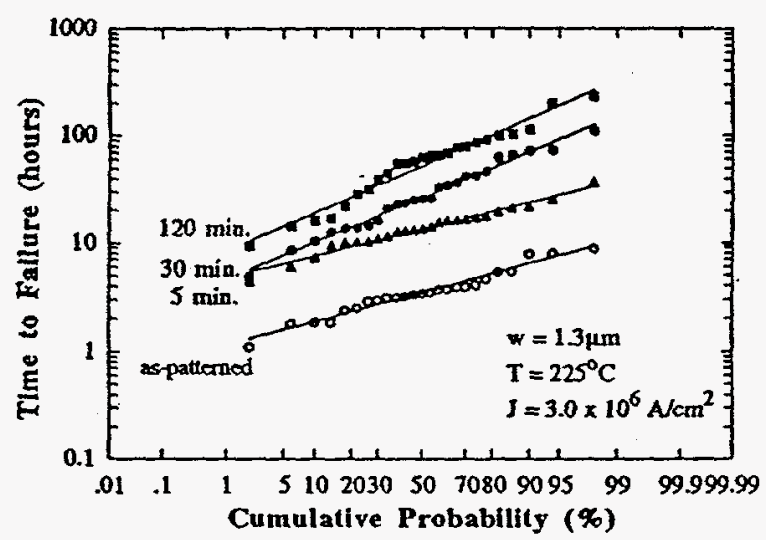

Fig.5 Time-to-failure distributions with annealing times for $\mathrm{Al}-2 \mathrm{wt} . \% \mathrm{Cu}-1 \mathrm{wt}$. \%Si lines. The distribution of 60 min.-annealed lines is not shown because it is almost same as that of 30 -min.-annealed lines.

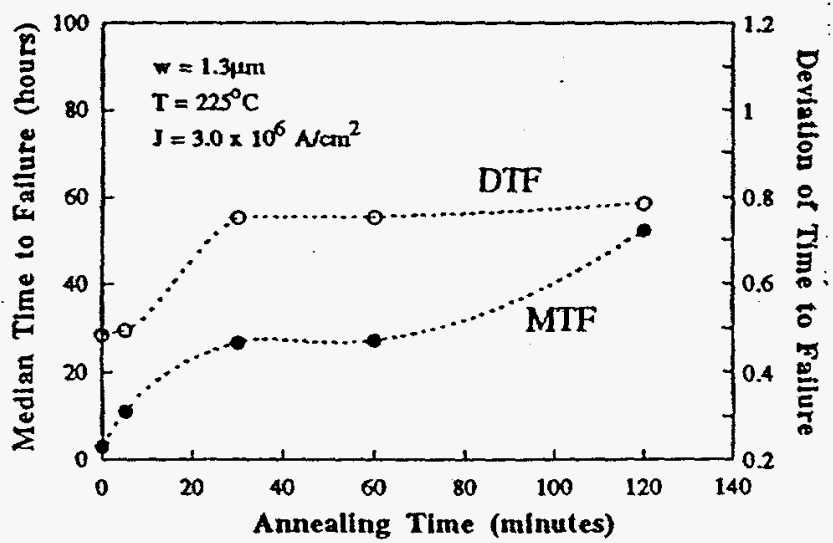

Fig. 6 Variations in MTF and DTF with annealing times for Al-2wt.\%Cu-1 wt.\%Si lines. 
The MTF variation shown in Fig. 5 resembles that pure Al lines shown in Fig. 2, except that there is no decrease in MTF after a short period of annealing. This difference has a simple explanation. The initial decrease in the MTF of the Al lines was attributed to the formation of bamboo grains. The microstructure of the as-patterned lines of $\mathrm{Al}-\mathrm{Cu}-\mathrm{Si}$ already contains bamboo grains which define polygranular segments (Fig. 7). Hence the preferential failure sites were present before the annealing was performed. The major changes during annealing were a decrease in the lengths of polygranular segments and a coarsening of the grains within the polygranular segment, as expected from the results of pure Al lines. It follows that annealing enhances the electromigration resistance. On the other hand, the increase in lifetime with annealing time is not as dramatic as in pure $\mathrm{Al}$ lines. This appears to be due to a slower rate of grain growth in the $\mathrm{Al}-\mathrm{Cu}$ Si lines. Alloying elements such as $\mathrm{Cu}$ and $\mathrm{Si}$ are expected to interact with grain boundaries, inhibiting grain growth. It is also possible that the $\mathrm{Cu}$ contribution to the lifetime enhancement may be influenced by the development of near-bamboo structures, since the Cu distribution and its sweeping kinetics in a polygranular segment may depend on the length and the nature of the polygranular segment-

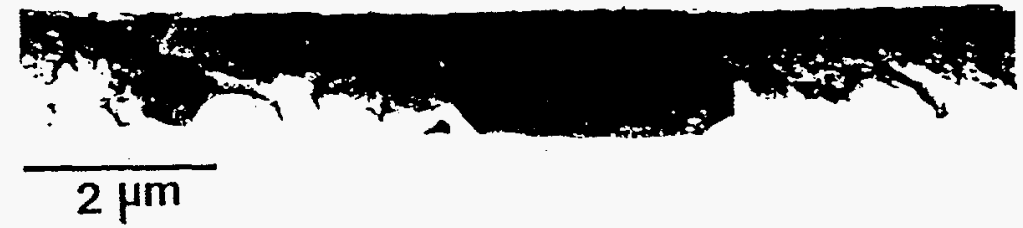

Fig. 7 TEM micrograph of a typical as-patterned microstructure in Al-2wt.\%Cu-1 wt.\%Si lines. A bamboo grain which exists with long polygranular segments is shown.

The saturation of the DTF also occurred in the Al-Cu-Si lines (Fig. 6). Interestingly, similar results were obtained for the study on Al-Sc alloys [11]. Therefore, it is plausible to conclude that annealing to create near-bamboo or perfect-bamboo structures increases the reliability of $\mathrm{Al}$-based interconnects.

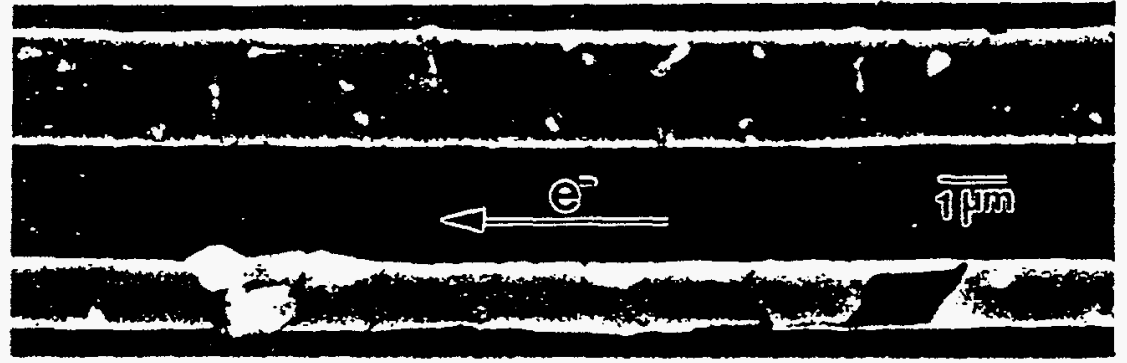

Fig. 8 SEM micrographs showing (a) a reference line which was not stressed by current and (b) a line after the failure under $\mathrm{J}=3.0 \times 10^{6} \mathrm{~A} / \mathrm{cm}^{2}$. Both lines were annealed for $30 \mathrm{~min}$. at $480^{\circ} \mathrm{C}$.

The typical failure morphology of the Al-Cu-Si lines is shown in Fig. 8. For the purpose of comparison, the microstructure of a reference line which was prepared by the same fabrication methods but was not stressed by current is also shown. Consistent with prior work [2], the failure void forms at the upstream end of a long polygranular segment, while a Cu-rich precipitate forms at the downstream end, and $\mathrm{Cu}$ is swept from the polygranular segment and a portion of the upstream bamboo grain prior to failure. 
Post-patterning annealing promotes bamboo-grain structures in narrow interconnects. When near-bamboo structures with short polygranular segments are developed, significant improvements in MTF and DTF are observed. However, the short polygranular segments still generate flux divergences at the ends of the polygranular segments and cause the formation of electromigration-induced voids in the bamboo grains at the upstream ends of the polygranular segments. Since the failure sites in Al-based narrow interconnects are fixed by the grain structure, the reliability of the interconnects can be significantly improved by controlling the grain structure.

\section{ACKNOWLEDGMENTS}

This work was supported by the Director, Office of Energy Research, Office of Energy Sciences, U.S. Department of Energy, under Contract No. DE-AC03-76SF00098 and by the U.S. Department of Energy at Lawrence Livermore National Laboratory, under Contract W7405-Eng-48. The authors are thankful to Dr. Michael Fluss for his help to support this work.

\section{REFERENCES}

1. M.J. Attardo and R. Rosenberg. J. Appl. Phys. 41, 2381 (1970).

2. C. Kim, and J.W. Morris, Jr., J. Appl. Phys. 73, 4885 (1993).

3. B.Miner, E.Atakov, A.Shepela, and S.Bill, in Materials Reliability in Microelectronics IV, edited by P.Børgesen, J.C.Coburn, J.E.Sanchez,Jr., K.P.Rodbell, and W.F.Filter (Mater. Res. Soc. Proc. 338, Pittsburgh, PA, 1994) pp. 333-338.

4. B.N. Agarwala, M.J. Attardo, and A.P. Ingraham, J. Appl. Phys. 41, 3954 (1970).

5. E. Kinsbron, Appl. Phys. Lett. 36, 968 (1980).

6. J. Cho and C.V. Thompson, Appl. Phys. Lett. 54, 2577 (1989).

7. K.Y. Fu, J. Appl. Phys. 69, 2656 (1991).

8. C.V. Thompson and H. Kahn, J. Electron. Mater. 22, 581 (1993).

9. Y.-C. Joo and C.V. Thompson, in Materials Reliability in Microelectronics IV, edited. by P.Børgesen, J.C.Coburn, J.E.Sanchez, Jr., K.P. Rodbell, and W.F. Filter (Mater. Res. Soc. Proc. 338, Pittsburgh, PA, 1994) pp. 319-324.

10. J.R. Lloyd, ibid, pp. 367-372.

11. C.Kim, S.H. Kang, F.Y. Génin, and J.W. Morris, Jr., in this volume. 